\title{
CONSTRAINTS IN THE IMPLEMENTATION OF CONTINUING PROFESSIONAL TEACHER DEVELOPMENT POLICY IN THE WESTERN CAPE
}

\author{
L. A. Johns* \\ Professional development and matters, NAPTOSA \\ e-mail: lynnej@naptosa.org.za
}

\section{Z. C. Sosibo*}

Senior Phase and Further Education and Training Department

e-mail: SosiboL@cput.ac.za

${ }^{*}$ Cape Peninsula University of Technology

Cape Town, South Africa

\section{ABSTRACT}

Continuing teacher professional development (CPTD) is regarded as key to teachers gaining essential pedagogical-content knowledge needed for the 21st century. Despite the existence of formal structures for this system in South Africa, policy implementation continues to present challenges. This study investigated constraints in the implementation of CPTD policy. The research question was "What factors inhibit the implementation of CPTD policy in Western Cape education districts?" The design was a qualitative case study with purposely-selected sample of principals, teachers, and provincial and district officers. Data were collected through semistructured interviews and triangulated through document analysis. Data analysis involved colourcoding, categorisation and emergent themes. Results revealed that CPTD implementation frustrated teachers, resulting in negative attitudes, low morale and demotivation. Teachers perceived the CPTD as a compliance activity rather than as a tool for growth and development. This conclusion could imply that policymakers need to rethink ways of improving CPTD implementation.

Keywords: continuing professional teacher development, policy implementation, constraints, compliance

\section{INTRODUCTION}

Governments around the world have identified continuing professional teacher development (CPTD) as a way of enhancing teachers' content and pedagogical knowledge relevant for the 21 st century educational challenges (Hardy 2012). Morrow (2007) believes that CPTD could also be about upgrading teachers' knowledge where it is lacking. In South Africa the National Department of Education (NDoE) regards CPTD as a key priority and an important educational 
initiative to improve schooling and, ultimately, learner achievement (Carrim 2013). Consequently, participation in CPTD is compulsory for all teachers. Section 7 of the South African Council for Educators (SACE) Code of Ethics (SACE 2013, 8) states that teachers must "keep abreast of educational trends and developments". To various activities SACE allocates points that the educators accumulate within a three-year cycle (Organisation for Economic Cooperation and Development (OECD) 2008), whereas the Department of Basic Education (DBE) develops and oversees CPTD policy in relation to the Norms and Standards for Educators (Carrim 2013).

In spite of the emphasis on the importance of CPTD in South Africa, challenges have been identified in this system. According to Singh (2011), the professional development of teachers in South Africa has been erratic, leading to the decline in the quality of teachers. Despite there being formal structures in place, policy implementation continues to be a problem. Steyn (2011a) identifies quality leadership provided by school principals and education officials as an aspect that significantly influences effective implementation of CPTD policy. Regrettably, other studies also suggest that effective leadership is lacking (Whiteworth and Chiu 2015; Steyn 2011b). These findings raise concerns, as they imply that CPTD policy is not being implemented effectively. Research done by Onwu and Sehoole (2015) reveals that the current institutional structures cannot provide comprehensive CPTD.

The purpose of this study was to identify constraints hindering the implementation of CPTD in the Western Cape Province. The research question was "What factors inhibit the implementation of CPTD policy in Western Cape Education Districts?" The results of this study should contribute meaningfully to existing knowledge in the area of CPTD policy implementation locally and internationally. Locally, results can influence education policymakers at the levels of the Department of Basic Education and Training, SACE and the Western Cape Education Department (WCED) to rethink ways in which CPTD could be effectively managed, monitored and implemented. Internationally, scholars from developed countries can draw on policy implementation experiences of teachers in a developing country. Furthermore, other stakeholders, such as educators, teacher unions and trainers might benefit from the results of this study, in that they can reflect on them and, if possible, find ways to improve the manner in which they implement CPTD.

\section{LITERATURE REVIEW}

\section{Conceptual definition of Continuing Professional Teacher Development}

The teaching and learning process is not static, but it always evolves. Consequently, SACE 
(2013) requires teachers, as professionals, to continuously develop their knowledge and skills. CPTD, or teacher learning (TL), as it is referred to by Msomi, Van der Westhuizen and Steenekamp (2014) cannot be viewed as a once-off occurrence, "but [as] a continued process, requiring time and effort". CPTD assists in-service teachers in keeping up to date with the everchanging school environments (Mpahla and Okeke 2015, 11). Moreover, Diale (2016, 95) emphasises that in-service training is an important aspect in the career development of teachers. This on-going learning provides teachers with necessary support through professional development activities such as workshops and courses. These activities equip teachers with powerful pedagogical subject knowledge, an understanding of how students think, and strategies to improve classroom practice (Caena 2011). Hardy (2012) asserts that CPTD is not just about workshops and courses made available to teachers by bureaucrats, but, rather, that it is a situated socio-political practice, and, as a result, its support is intrinsically political. This notion emphasises the fact that CPTD depends on the relationship between the context in which it (needs to) takes place and stakeholders in education who create opportunities for such development. CPTD is context-bound, in the sense that the knowledge gained from it is used in the same context as that from which it was acquired. Moreover, Leibowitz, Vorster and Ndebele (2016) emphasise that a contextual approach to professional development allows for an understanding of how to strategise and effect teaching and learning. Therefore, CPTD falls within the realm of situated learning (Lave and Wenger 1991). Evans (2014) advocates that CPTD opportunities need not be "intentional" or planned, but rather that they be incidental. Incidental learning is not planned and happens every day in and outside schools.

There is a belief that CPTD is a perfect answer to sustainable change in schools (Steyn 2011a). This means that teachers will be better equipped to deliver the curriculum and that being so, the academic results of students will improve. In their study on CPTD in rural areas, Mpahla and Okeke $(2015,30)$ make two significant recommendations: that policymakers need to appreciate the fact that quality education is reliant on teacher professional development and that teacher professional development is a human right to which all teachers must have access. Conversely, not providing teachers with opportunities for growth and development is a violation of their human rights. It would appear that lack of opportunities for teachers to improve their knowledge and skills strips them of the confidence they need to impart knowledge and provide quality education.

The focus of CPTD should be on the quality of professional growth among teachers in order to improve practice. Sadly, this is not always the case. Tooley and Connally $(2016,2)$ express a concern that the American education system has been more successful in producing professional development (PD) quantity than quality. They argue that Americans spend 
millions of dollars per year on PD, but there is little evidence as to how effective the development has been in improving teacher practice and student learning. In fact, research conducted by the organisation, The New Teacher Project (TNTP), shows that there is no significant difference with regard to professional practices between the teachers who attended PD workshops and those who did not (Tooley and Connally 2016, 2). These findings are disconcerting, if weighed against the background that the goal of CPTD is to bring about knowledge and skills that in turn change the instructional practices of teachers.

\section{Professionalism in continuing professional development}

Professionalism is pivotal to CPTD. Professionalism can be defined as "the repertoires of professional knowledge, attitudes, and values which articulate the character of teachers' practices" (Murray 2014, 8). Evans (2014) avers that the focus should be on developing the professionalism of teachers and not on expecting CPTD to bring about change. This is particularly important, in that, as professionals, teachers should automatically develop and not be coerced into developing. CPTD not only enhances teaching and learning, but also ensures that classrooms have highly skilled teachers. Ultimately, learner performance is promoted (Mpahla and Okeke 2015). Nonetheless, the reality is that only some teachers see PD as a professional duty, whereas many others view it as optional (Caena 2011). Another reality is that PD has a poor reputation among teachers and those who study education (Tooley and Connally 2016), a view that results from developmental opportunities that are not seen as relevant, especially in rural areas (Mpahla and Okeke 2015). Sadly, this situation might result in the teachers' not committing to PD, leading to missed opportunities for growth.

Watson's (2013) assertion, that PD plays an important role in teacher professionalization, coincides with Evans's (2014). Watson holds that professional development should relate solely to the teacher (as an individual) and that the secondary beneficiaries (learners) should not be considered in any definition of this concept. This means that the primary focus of CPTD should not be improved learner performance, but teacher professionalism. Evans's (2014) conceptualisation of professionalism is multidimensional and is based on three components: behavioural, attitudinal and intellectual development. For further elaboration on these types of development, please read Evans (2014).

\section{Developments in policy implementation}

According to Cerna (2013), policies are successful, mean something, or become significant only if they are implemented well. Implementing policy effectively demands individual, as well as collective action so as to achieve desired goals (Coburn 2016). In order to achieve these 
desired goals, productive PD requires a theory of action (Tooley and Connally 2016), which requires education leaders to support teachers in engaging with high quality PD, the result of which is improvement in classroom practice and overall increased student learning and achievement. Tooley and Connally (2016) suggest that the basic theory of action framework should be implemented as an ongoing cycle of action comprising four steps: needs identification, selection of effective approaches, implementation of quality approaches, and assessment of PD outcomes. Clearly, the theory of action framework is synonymous with action research. If results show that the purpose has not been achieved during the first cycle of the theory of action, a new one begins again until the needs have been met or results show improvement.

In his research on the role of staff development in the professional development of teachers, Singh (2011) found that professional development needs to be structured, and that an unstructured approach to implementation often results in schools and teachers not implementing policy. Hence the recommended basic theory of action framework for professional development by Tooley and Connally (2016). If implemented effectively, this framework could result in action and effective implementation of CPTD policy.

Research has identified key aspects that may influence the successful implementation of PD (Steyn 2011b). These aspects include emphasis on teachers' learning, commitment of teachers, effective leadership, particular school context, and feedback on teachers' development. Seeing that teachers' needs vary from context to context, it is important for PD programmes to be differentiated and practical in nature so as to meet those diverse developmental needs. The commitment of teachers is vital, they must want to learn and to grow professionally. Motivation for this growth must be intrinsic. In order for teachers to be committed and to take ownership of their development, Du Toit-Brits $(2018,57)$ proposes that learning be self-directed. A self-directed approach to development would influence the lives of teachers and ultimately impact on the classroom. Effective leadership also contributes to teachers' professional growth. This implies that school principals must be involved in the learning process and in identifying the developmental needs of their teachers, and that they must provide teachers with suitable developmental opportunities (Steyn 2011b). Particular school aspects, such as school culture and teacher collaboration may influence teacher development and commitment. A conducive environment for professional development is generated when teachers and leaders collaborate in the context of professional learning communities (Fullan 2006). In addition, feedback on teachers' development needs to be ongoing and thorough, and teachers need to know whether or not they are making progress when implementing what they have learned (Steyn 2011b). 
Unfortunately, it is not always easy to pinpoint definite factors that result in successful CPTD policy implementation, as they depend on political, economic and social contexts (Cerna 2013), as pointed out earlier. This could explain why a one-size-fits-all policy approach is ineffective (Watson 2013). Some scholars have tried to identify factors that influence successful implementation and results vary from context to context. Whiteworth and Chiu (2015) found that contextual factors such as teacher experience, motivation, self-efficacy, school culture and working conditions play an integral role in teacher change and development. That may explain why Fullan (2006) emphasises context as one of the critical elements that needs to be emphasised in policy implementation, and, I would add, in policy formulation as well.

\section{Theoretical framework}

This study is underpinned by Fullan's theory of change (Fullan 2006). According to Fullan (2007), three factors undergird implementation of policy: characteristics of change, local roles and external factors. Characteristics of change are based on the following four variables: need, clarity, complexity and quality, practicality. Hardy (2012) avers that many CPTD programmes or policies do not directly address the needs of teachers. Consequently, some teachers do not see the need for advocated change. Clarity is often a challenge during the change process, probably because the reason for and the process of change are not clearly defined and understood by stakeholders responsible for policy implementation (Fullan 2006; 2007). This means that the stakeholders involved in the implementation are not informed as to why change is required and how change will be implemented. Complexity is about the degree of difficulty of the change required by those accountable for implementation (Fullan 2007). Some of the aspects taken into account when measuring difficulty include skills required, alterations in beliefs and the use of materials (Fullan 2007). The more complex a CPTD policy is, the less likely that it will be implemented effectively. The quality and practicality of a new programme or policy also depend upon the history of change and implementation. Ambitious policies, however, tend to be politically driven (Fullan 2007). In other words, politicians use policy to bring about educational or societal change for political gains. Unfortunately, politically-driven policies usually do not last long, but have short timespans between initiation and implementation, thus impacting negatively on the quality and practicality of implementation (Fullan 2007). Since the dawn of democracy, this has been the reality in the South African education system. Policies have been frequently replaced with new ones without evidence of the improvement of the education system or learner achievement. Some of these policies, to name but a few, have included Curriculum 2005, Outcomes-based education; National Curriculum Statements (NCS); Curriculum and Assessment Policy Statements (CAPS). 
Local factors that influence CPTD policy implementation focus on the context or social conditions in which change must occur (Fullan 2007). Not every local school system is the same: what might work in one context might not work in another. A local school system consists of the following stakeholders: district, community, principals and teachers (Fullan 2007). Each local school system has a professional learning culture that is dictated by context and various socio-political cultures. Fullan $(2007,18)$ points out that change or implementation fails when "the infrastructure is weak, unhelpful, or working at cross purposes", a fact supported by Singh (2011). The infrastructure referred to consists of the different ecological levels within the education system, namely teachers, school, education district, provincial and national departments of education. What this means is that a teacher cannot effect sustainable change within a school that does not have a structured approach to policy. Similarly, a school cannot effect sustainable change if support from the district is not forthcoming. Likewise, a district cannot effect sustainable change if it is not supported by the provincial department of education. In a nutshell, in order for policy implementation to be successful, all levels of the education system need to be supportive and have a common purpose.

External factors involve the broader society, which plays an integral role in decisions made concerning any education system. Provincial and state priorities for education are based on political decisions lobbied for by interest groups, bureaucrats and elected representatives. It is thus the concerns of broader society that put pressure on schools and districts (Fullan 2007). The fragmented approach and lack of coherence among external parties, such as nongovernmental organisations (NGOs), non-profit organisations (NPOs), higher education institutions (HEIs) and teacher unions mean that all compete for teachers' time. These external stakeholders offer similar programmes to teachers, thus limiting the teachers' abilities to participate fully in any programme. A divide has also been noted between policymakers and practitioners. One party is unaware of the subjective world of the other. There seems to be no relationship between local school systems and external authorities such as policy-makers, resulting in the lack of clarity and ambiguity about expectations when it comes to policy implementation (Fullan 2007).

Fullan (2007) asks how policy can change this dysfunctional culture. Although Fullan (2006) highlights some concerns regarding professional learning communities (PLCs), they might bring hope for collaboration, rather than competition, among different stakeholders. Fullan $(2006,6)$ describes the role of PLCs as "involv[ing] developing communities of learners in which teachers and school leaders work together to improve the learning conditions and results of students in given schools". 


\section{METHODOLOGY}

A qualitative case study of CPTD policy implementation in two education districts was employed in this investigation. The aim of qualitative research is to study the experience and, social situations of the phenomenon in its natural setting (Rule and John 2011). According to Punch and Qancea (2014), a case study allows for an in-depth understanding of the subjective experiences of participants in a study, taking into account the complexity of their context. Qualitative case study was considered appropriate for this study, because it provided participants with an opportunity to offer rich data about their experiences of CPTD policy implementation in their natural settings.

Site selection involves identification and justification of a site to locate participants involved in the study (McMillan and Schumacher 2010). The sites in this study were two district offices, four schools and one provincial office. The Western Cape Province consists of eight education districts. Four of the eight districts are situated in rural areas and four in urban areas. This study was conducted in two of these districts that were conveniently sampled. Districts were chosen on the grounds of their close geographical positioning to where the researcher resides, thus ensuring the economic viability of the research. Two schools were purposely selected from each of the two districts, with one being a primary and the other a high school. Criterion for the selection of these schools was their excellent results in 2016 systemic tests, in which each had a pass rate of more than $80 \%$. The assumption in selecting these schools was based on Carrim's (2013) assumption that teachers at schools with excellent results participate in professional development.

Two sampling strategies were used in the selection of the participants for this study, namely purposive and convenience sampling. Purposive sampling is also referred to as judgement sampling, in that the researcher deliberately chooses informants or participants according to the knowledge and experience they might possess (Dolores and Tongco 2007). Convenience sampling was used because of practical constraints, such as availability and the close geographical positioning of participants. Thus, the sample consisted of participants who were available and were willing to participate in the study (Johnson and Christensen 2010), and who were able to contribute rich data to this study. A total of four school principals (one from each of the four schools), two district officials (one from the urban district office and the other from the rural district office), one provincial official from the provincial office and 24 teachers (six from each of the four schools) participated in this study.

Instead of their real names, the following codes were used to refer to the sites and participants: School 1-School 4 for the schools, PO for the Provincial Officer, RDO for the rural district officer and UDO for the urban district officer. For school principals, the codes were 
SP1, SP2, SP3 and SP4, and for teachers they were ST1-ST6 for School 1; ST7-ST12 for School 2; ST13-ST18 for School 3; and ST19-ST24 for School 4.

Data was collected using semi-structured open-ended individual interviews with PO, RDO, UDO and the four principals, whereas focus-group interviews were conducted with teachers. Individual interviews allowed the researcher to have a conversation with participants, thereby gaining invaluable insight into their views and beliefs about the phenomenon studied, and focus-group interviews allowed them to share and discuss their feelings and express opinions that are unique to them regarding the same phenomenon (Strydom and Bezuidenhout, 2014). Interviews were recorded with the permission of the participants.

Data triangulation involves the use of more than one research method to collect data in a study (Koonin 2014). For this study, data obtained through interviews was triangulated with data from documents related to CPTD, namely The National Policy Framework for Teacher Education and Development (NPFTED) (2006) and the Integrated Strategic Planning Framework for Teacher Education in South Africa (ISPFTED) (2011). The credibility of this study was ensured by the use of data triangulation which was done through the use of different data sources (provincial and district officials, teachers and school principals) and datacollection methods (interviews and document analysis). For analysis, data obtained through the interviews was synthesised with that obtained from documents. After the synthesis, data was compared and contrasted, colour-coded, categorised and classified into emergent themes that were later used as subheadings for the findings.

Ethical considerations included obtaining permission from the Western Cape Education Department to conduct the study. Ethical clearance to conduct the study was obtained from the Cape Peninsula University of Technology Ethics Committee. In addition, education districts and the principals also gave permission for the study to be conducted in their districts and schools. Teachers participated voluntarily in the focus group discussions, but they also signed consent forms. They were informed about the contents of the study, their voluntary rights and that their anonymity would be assured. The researcher explained to them that data obtained would be used solely for this research and that it would be stored in a safe place and discarded after three years.

\section{RESULTS}

The two themes that emerged from data analysis were teachers' negative attitudes and lack of motivation, and secondly, compliance and coercion. They are presented in the next section. 


\section{Negative attitudes and lack of motivation}

The departmental officials, principals and teachers expressed different opinions about the constraints they experienced with regard to the implementation of CPTD policy in their region. Teachers expressed feelings of demotivation, distrust and frustration with the manner in which CPTD policy was implemented and with them not being treated as professionals. To illustrate this point, ST4 stated:

"By completing a register for every activity attended, we feel belittled as professionals. They [WCED and SACE] distrust teachers, as we are just a PERSAL [personal salary] number to the department."

With this utterance, ST4 was suggesting that their department did not take them seriously, but that it treated them as numbers, rather than human beings. According to the National Policy Framework for Teacher Education and Development (NPFTED - Government Gazette, 26 April 2007) (DBE 2007, 19), however at the heart of the CPTD system is the enabling and empowerment of the teachers. Advocacy of the CPTD programme should be capable of reassuring teachers that they stand to benefit from it and gain greater professional confidence. The NPFTED thus emphasises and reinforces the professional status of the teachers. Nonetheless, based on their statements, it was clear that participants were becoming frustrated and developing a negative attitude and low level of motivation towards the CPTD policy.

RDO mentioned that staff development teams (SDTs) were training teachers, but not directing them towards developmental critical thinking. He emphasised that SDTs should assist teachers in "making the mind-shift around cultivating a professional attitude towards your work". ST16 was of the opinion that very few teachers wanted to change their practice, a view also held by ST8, who mentioned that teachers had a negative mind-set towards CPTD due to various factors, including large classes and inadequate resources. Similarly, ST15 pointed out that the current defiant mind-set of teachers was hard to change. Some of the participants indicated that they were not willing to use the CPTD website in its current state, which they perceived as dysfunctional. This unwillingness was confirmed by ST17, who commented:

"I'm not going to go onto that @\#@ website. I am not going to enter it until its user-friendly."

In contrast, PO felt that there was training fatigue and that developmental activities were not meeting the needs of teachers. He described CPTD activities as "a hit-and-miss exercise", which he claimed resulted in a negative attitude among teachers. Moreover, there was a feeling among participants that the manner in which CPTD policy was implemented was not 
constructive. ST10 mentioned that subject advisers who visited their school only monitored and verified the work of teachers, but that no positive criticism was given or motivation with regard to development and training. In support of ST10, ST12 asserted that,

"At the end of the subject advisers' visits I should be thanking them and not be upset and cross, as is the case right now. We need guidance and capacity development, not inspection."

In its policy on the Organisation, Roles and Responsibilities of Education Districts, (DBE 2013), the DBE clearly specifies the four main functions of education districts: planning; support; oversight and accountability; and public engagement. Planning and support speak directly to CPTD and specify that districts should assist schools with compiling their improvement and development plans, then integrate these plans into district plans. Regarding support, districts are expected to provide an enabling environment by organising the provision of and support for, the professional development of managers, educators and administrative staff members. One of the core functions of the district curriculum delivery support team is to inform schools about national and provincial policies and to assist them with their implementation. Furthermore, the support team is supposed to promote and organise professional development activities for educators in cooperation with the SACE (DBE 2013: 21). The frequent use of the word "assist" is an indication that it is central to the CPTD policy. Thus, the main role of a district office is to offer support to schools and not only to monitor and evaluate. The Integrated Strategic Planning Framework for Teacher Education and Development in South Africa (ISPFTED 2011, 162) addresses this issue by recommending that there needs to be a clear differentiation between an advisory and an inspectoral role for subject advisers. Yet, as illustrated by the remarks of ST10 and ST12, this was not the case, as subject advisers seemingly paid more attention to monitoring and evaluation, rather than to providing support.

\section{Compliance and coercion}

Results revealed that the departmental officials, principals and teachers believed that the CPTD policy was compliance-driven and that its implementation was forced on them. According to RDO, CPTD policy was implemented for political reasons in order to comply with legislation and not necessarily to help teachers to grow and develop as professionals. UDO expressed dissatisfaction, in that by instructing districts to organise training teams, the provincial district was foisting the responsibility of implementing CPTD policy on to them (district officials). RDO and UDO agreed that this approach to policy implementation resulted in CPTD becoming 
a compliance and superficial activity rather than a developmental and purpose-driven exercise. Some principals concurred, with SP4 expressing a view that, "I think that it [CPTD] is one of those things that people have to do".

This opinion could be interpreted to mean that CPTD is one of those things that have to be done for the sake of doing them, not necessarily because it has any value. This view was supported by SP3 who mentioned,

"What worries me about the policy at present is that it's become a tick-box exercise. People will follow the path of least resistance. They'll go the way that seems to get them to that point best, but whether they're really genuinely enthusiastic about being developed, you'll never really know, because they've got enough points."

Many of the teachers seemed to agree that SACE was forcing the CPTD policy on them, a situation about which ST3 made this comment,

"When workshops are compulsory to attend, then you know you're organising workshops for the sake of organising them."

ST3's statement may not necessarily be true in all cases, as some workshops may be compulsory because of the value they hold for those who have to attend them. On the issue of coerced implementation, ST14 mentioned that in the two and half years that he had been at the school, the CPTD policy had been mentioned and they had been "told" to implement it. ST20 believed that forced compliance and implementation had resulted in the teachers' becoming resistant towards the policy. An example of such resistance was evident in the question that ST2 asked, namely: "Why should a senior teacher who delivers the results be forced to attend workshops?"

Another apparent problem with implementation was that a one-size-fits-all approach was allegedly adopted by authorities. ST13 referred to this phenomenon as a "generalised approach to teacher development", meaning that contextual factors were often not taken into account when implementing CPTD policy, as Fullan (2006; 2007) suggests they should be. Teachers in rural districts felt that there were different dynamics in rural and urban contexts and that those dynamics needed to be taken into account when implementing CPTD policy, with ST5 claiming that,

"Rural schools have different needs to urban schools. What works in an urban environment might not work in a rural environment."

An example of such a dynamic as given by ST5 was that rural school teachers needed to travel 
long distances to attend compulsory CPTD workshops. In his view, that had a negative impact on curriculum delivery, as teachers were compelled to leave school early to attend the workshops, which negatively impacted their notional teaching time. According to the NPFTED (DBE 2007), teachers should not neglect their main responsibility of teaching in order to earn professional development points. Clearly, provision needs to be made for teachers to attend CPTD workshops without feeling guilty about abdicating their responsibilities.

There was a feeling among some teachers that their voices were not heard in the formulation and implementation of the CPTD policy. This might be what led ST18 to describe the CPTD policy implementation as top-down. This sentiment was substantiated by RDO, who stated, "I cannot say that one orientation session to CPTD automatically creates buy-in for the teachers". An example of the lack of buy-in among teachers was expressed by SP1, who said,

"We don't get to implementing CPTD policy fully in schools. We don't get to it as we don't have meetings to discuss what we have learned. I would be lying if I said we did."

From SP1's words, one can sense a feeling of frustration and desperation that much more should be done in the implementation of the CPTD policy. What is profound about these results is that the manner in which policy is implemented in this province negatively affects stakeholders at different levels of the system.

\section{DISCUSSION AND ANALYSIS}

Based on the results obtained in this study, it appears that the implementation of CPTD policy in the Western Cape Education Districts has constraints. If these constraints are not addressed, they can diminish the good intentions of providing CPTD programmes to teachers. These constraints, albeit few, touch at the core of CPTD. This is because CPTD is provided to teachers so that they can acquire the knowledge and skills that will enable them to improve their instructional practices, while at the same time they keep abreast of new developments in their fields.

The two themes that emerged paint a bleak picture about how CPTD policy is implemented in this province. One of the themes revealed that teachers do not feel valued, but are treated as numbers, and that the CPTD system is a tick-box or cut-and-paste activity that is done for reasons other than to develop teachers. Teachers reported that they do not perceive its importance, which has led to their developing negative attitudes and lack of motivation, as well as possible low morale. Fullan $(2006 ; 2007)$ argues that clarity is required in order for change to occur. If the reason for and the process of change are not clearly defined and understood by 
stakeholders, they will not be motivated to implement policy.

Results of this study have shown that what is reported to be happening on the ground contradicts what is stipulated in the policy documents about how CPTD policy should be implemented. Policy acts as a guide to the actions to be taken. If it is not adhered to or implemented effectively, as was found in this case study, actions taken render that policy ineffective at best and obsolete at worst, as reported in this study. In addressing the discourse between policy and implementation, Fullan (2007) concedes that ambitious policies tend to be politically driven and have short timespans between initiation and implementation. Thus, resulting in a rushed implementation phase lacking the four variables characteristic of change: need, clarity, complexity and quality, practicality.

What was also found to be disconcerting from the results was that it was not only the teachers who believed that policy implementation had constraints, but other stakeholders as well, including SPs, RDOs and UDOs. Ironically, even the PO, who would ideally be expected to speak highly of the policy implementation, was open about the issue of the CPTD policy's not meeting the needs of the teachers. It is imperative that the developmental needs of teachers are met, as each school system is not the same, similarly the needs of teachers (Fullan 2007). If the developmental needs of teachers are not met, they will not participate readily in developmental programmes offered.

It was also highly disturbing to note that contextual factors do not appear to be taken into consideration in the implementation of CPTD policy in this province. Fullan's $(2006 ; 2007)$ change theory emphasises the importance of context. Since the context of schools and districts is not homogeneous, policy implementation should take those varying contexts into consideration, instead of using a one-size-fits-all approach. Similarly, it does not bode well that there is no synergy among stakeholders with regard to the manner in which they implement CPTD policy. This is where Professional Learning Communities (PLCs) feature, as they can bring the stakeholders together to share experiences and learn from one another. Fullan (2006, 6) holds that PLCs "are in fact about establishing new collaborative cultures" that are highly needed in the context of this study.

\section{CONCLUSION}

The purpose of this study was to investigate constraints in the implementation of the CPTD policy in the Western Cape Province. Results showed that the flaws in the manner in which policy is implemented resulted in teachers' developing negative attitudes and lack of motivation, and that they experienced policy implementation as a compliance activity which did not assist them in developing as professionals. In addition, they felt that policy was forced 
on them from the top down, and that the right hand did not know what the left hand was doing. Clearly, the approach adopted in CPTD policy implementation lacks cohesion. In light of the above, it is recommended that the provincial leaders go back to the drawing board to rethink ways in which to ameliorate this situation. One of the recommendations would be to adopt the bottom-up approach and involve all the stakeholders, not only in the implementation, but in policy formulation as well. The other recommendation is that the provincial office undertake large-scale research on CPTD policy implementation in order to hear more voices. Another avenue for further research include extending the present study to Trade Unions (as an external stakeholder), so as to establish how they contribute or assist in implementing CPTD policy. The results of this study are not even the tip of an iceberg compared to the findings that could be made from large-scale research. After the CPTD system has been revisited, it is recommended that PLCs be established to encourage stakeholder collaboration. Although this study was small-scale, it has contributed immensely to existing knowledge in the area of CPTD.

\section{REFERENCES}

Caena, F. 2011. Literature review, quality in teachers' continuing professional development. Brussels: European Commission Directorate-General for Education and Culture. (Google Scholar).

Carrim, N. 2013. The search for quality education in post-apartheid South Africa, ed. Y. Sayed, A. Kanjee and M. Nkomo, 39-60. Cape Town: HSRC Press.

Cerna, L. 2013. The nature of policy change and implementation: A review of different theoretical approaches. Geneva: OECD. (Google Scholar).

Coburn, C. E. 2016. What's policy got to do with it? How the structure-agency debate can illuminate policy implementation. American Journal of Education 122: 465-475.

DBE see Department of Basic Education.

Department of Basic Education. 2007. National Policy Framework for Teacher Education and Development. Government Gazette, 26 April 2007. Government Printer, Pretoria.

Departments of Basic and Higher Education. 2011. The Integrated Strategic Planning Framework for Teacher Education and Development in South Africa. Pretoria: Departments of Basic and Higher Education.

Department of Basic Education. 2013. Organisation, Roles and Responsibilities of Education Districts. Pretoria: Government Printer.

Diale, B. M. 2016. Life orientation teachers' career development needs in Gauteng: Are we missing the boat? South African Journal of Higher Education 30(3): 85-110.

Dolores, M. and C. Tongco. 2007. Purposive sampling as a tool for informant selection. Ethnobotany Research \& Applications 5: 147-158.

Du Toit-Brits, C. 2018. Towards a transformative and holistic continuing self-directed learning theory. South African Journal of Higher Education 32(4): 51-65.

Evans, L. 2014. Leadership for professional development and learning: enhancing our understanding of how teachers develop. Cambridge Journal of Education 44: 179-198.

Fullan, M. 2006. Change theory: A force for school improvement. Seminar Paper Series No. 157. Jolimont, Victoria: Centre for Strategic Education (CSE).

Fullan, M. 2007. The new meaning of educational change. $4^{\text {th }}$ Revised edition. New York: Teachers 
College Press.

Hardy, I. 2012. The politics of teacher professional development. New York: Routledge.

Johnson, B. and L. Christensen. 2010. Educational research: Quantitative, qualitative and mixed approaches. New York: SAGE.

Koonin, M. 2014. Validity and reliability. In Research matters, ed. F. du Plooy Cilliers, C. Davis and R. M. Bezuidenhout, 252-261. Cape Town: Juta \& Company.

Lave, J. and E. Wenger. 1991. Situated learning: Legitimate peripheral participation. Cambridge: Cambridge University Press.

Leibowitz, B. L., J. Vorster and C. Ndebele. 2016. Why a contextual approach to professional development? South African Journal of Higher Education 30(6): 1-7.

Murray, J. 2014. Teacher educators' constructions of professionalism: A case study. Asia-Pacific Journal of Teacher Education 42(1): 7-21.

Morrow, W. 2007. What is teachers' work? Journal of Education 41: 1-20.

McMillan, J. H. and S. Schumacher. 2010. Research in education: Evidence-based inquiry. Seventh edition. New Jersey: Pearson Education Inc.

Mpahla, N. E. and C. I. O. Okeke. 2015. Junior secondary educators' views on the strategies for implementing continuing professional development programs in one rural education district. Student Tribals 13(1): 22-33.

Msomi, W. N., G. J. van der Westhuizen and K. Steenekamp. 2014. Teacher professional learning in the context of policy implementation. South African Journal for Higher Education 28(3): 798-815.

OECD see Organisation for Economic Co-operation and Development.

Organisation for Economic Co-operation and Development 2008. Reviews of National Policies for Education, South Africa. OECD, Paris.

Onwu, G. O. M. and C. T. Sehoole. 2015. Why teachers matter: Policy issues in the professional development of teachers in South Africa. University of Pretoria: Pretoria Press.

Punch, K. F. and A. Qancea. 2014. Introduction to research methods in education. London: SAGE Publications.

Rule, P. and V. John. 2011. Your guide to case study research. Cape Town: Van Schaik.

SACE see South African Council for Educators

Singh, S. K. 2011. The role of staff development in the professional development of teachers: Implications for in-service training. South African Journal of Higher Education 25(8): 1626-1638.

South African Council for Educators. 2013. The CPTD management system handbook. Pretoria: SACE.

Steyn, G. M. 2011a. Continuing professional development in South African schools: Staff perceptions and the role of principals. Journal of Social Science 28(1): 43-53.

Steyn, G. M. 2011b. Implementing continuing professional teacher development: Policy and practice. Acta Academica 43(1): 210-232.

Strydom, A. and R. M. Bezuidenhout. 2014. Qualitative data collection. In Research matters, ed. F. du Plooy-Cilliers, C. Davis and R. M. Bezuidenhout, 173-194. Cape Town: Juta \& Company.

Tooley, M. and K. Connally. 2016. No panacea: Diagnosing what ails teacher professional development before reaching for remedies. Washington, DC: New America.

Watson, A. 2013. Teacher professionalization and professionalism: A literature review. Commissioned by JET Education Services. Johannesburg: JET.

Whiteworth, A. and J. L. Chiu. 2015. Professional development and teacher change: The missing leadership link. Journal of Science Teacher Education 26(2): 121-137. 